\title{
A Study to Improve Student Service-learning: From Activity to Learning
}

\author{
Sahoon Kim1)
}

\begin{abstract}
The purpose of this study is to suggest a developmental plan for student service-learning by analyzing performance and problems. Students need service-learning to discover, plan, and implement local community issues on their own, away from the passive volunteer work. service-learning should include educational activities such as experiment, concrete experience, and reflection. It is time for expert opinion on how these activities will work out. Thus, this study conducted an in-depth analysis of the experiences of students, parents, and teachers, as well as changes in perception through the service-learning. As an interview method, a focus group interview (FGI) was conducted. Main issues are summarized as follows. First, it is necessary to redefine the concept of service-learning and diversify the types of service-learning. Second, cooperation should be diversified for the practical operation of service-learning. Third, professional organization is needed to ensure continuous cooperation between the school and the community. Fourth, a plan should be prepared to utilize the nature of service-learning and at the same time lead the growth of the teacher himself. Fifth, it is necessary to devise a way to ensure safety. It is hoped that this study will make the practice of service-learning widely known, and further develop concrete solutions to improve service-learning.
\end{abstract}

Keywords: Service-learning, Student Service-learning, Volunteering, Volunteer Work

\section{Introduction}

The purpose of this study is to suggest a developmental plan for student service-learning by analyzing performance and problems. Students need service-learning to discover, plan, and implement local community issues on their own, away from the passive volunteer work. Based on this need, a new service learning model was developed in 2016. And, a pilot project of service-learning was conducted in 2017 2018 with the autonomous local volunteer centers. In 2019, the Seoul Volunteer Center and the Seoul Metropolitan Office of Education promoted the 'Seoul-type Student service-learning' in earnest. The Seoul-style student service-learning practice school is a model in which the community, autonomous local volunteer centers, and schools

Received(January 20, 2020), Review Result(1st: February 22, 2020, 2nd: April 16, 2020), Accepted(May 27, 2020)

1) (Professor) 02450 Dept. Education, HanKuk Univ. of Foreign Studies, Imun-dong, Dongdaemun-gu, Seoul, Korea

email: kimsh@hufs.ac.kr 
have tried to build an operation support system to transform the paradigm of service-learning. As their experience has accumulated, it is time to offer a more advanced direction for service-learning. Thus, this study attempted to analyze the experiences of participants and to suggest developmental directions for service-learning.

\section{Theoretical Background}

Volunteer activities go beyond simple benefits and become the foundation of a society's sustainability and member trust[1]. The more active people are in solving community problems and helping neighbors in need, the stronger the trust and safety net in one society[2]. For this reason, many countries encourage, or sometimes mandate, students to participate in volunteer work[3]. In 1995, through the 'May 31 Education Reform Plan' in 1995, volunteer activities became part of the school curriculum.

On the other hand, in the era of the 4th Industrial Revolution, schools and students need volunteer activities to discover, plan and implement community problems on their own, away from the existing passive volunteer activities[4]. The concept of service-learning began to be used in the late 1960s[5-7]. service-learning emphasizes reciprocity, reflective reflection, and curriculum linkages between volunteers and beneficiaries[8]. Reciprocity means that students and beneficiaries are not one-sided, but equal. Indeed, service-learning should lead to students' learning and growth[9].

Service-learning can be embodied by applying Kolb's experiential learning theory model.

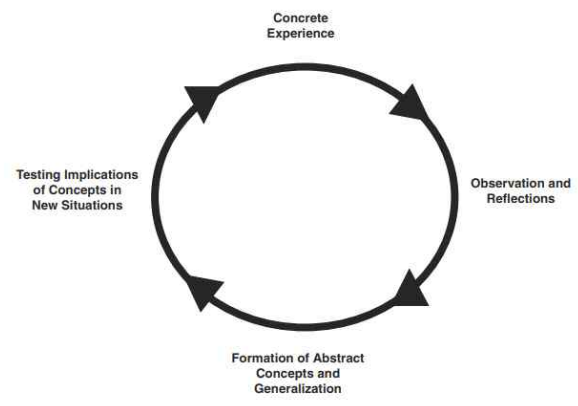

[Fig. 1] The Experience Learning Cycle[10]

According to the model, service-learning needs to be regarded as a new paradigm. It means that service-learning should include educational activities such as experiment, concrete experience, and reflection. 


\section{Research Methods}

This study conducted an in-depth analysis of the experiences of students, parents, and teachers, as well as changes in perception through the service-learning. Also, this study interviewed changes in values and emotions such as reward and humility, and whether or not to voluntarily participate in service-learning in their future. As an interview method, a focus group interview (FGI) was conducted. The focus group was divided into program participants such as students and parents, and program managers such as teachers, autonomous local volunteer centers, and community service groups. Semi-structured interviews were conducted to focus on the research content. Interviews with participants were conducted in terms of 'changing experience and perception of participation in the program', and interviews with operators were conducted in the aspect of 'program operation system'. The study subjects are as follows [Table 1].

[Table 1] Research Participants

\begin{tabular}{c|c|c} 
& Interviewees & number \\
\hline \multirow{2}{*}{$\begin{array}{c}\text { Participants for } \\
\text { service-learning }\end{array}$} & 1) Students & 10 \\
\cline { 2 - 3 } & 2) Parents & 3 \\
\hline \multirow{2}{*}{$\begin{array}{c}\text { Operators of } \\
\text { service-learning }\end{array}$} & 3) Teachers & 3 \\
\cline { 2 - 3 } & 4) Managers of volunteer center & 8 \\
\hline
\end{tabular}

\section{Results}

This chapter focuses on the stories of teachers and mentors who answered the most appropriate for the purpose of the study among the interviewees. The summary of all interviewees was covered in the next chapter.

\subsection{Teacher}

\subsubsection{The Need for Cultural Settlement: "I was a public enemy"}

An: I was a public enemy. At the beginning of the semester, at the teacher conference, I emphasized 
that our school is a Seoul-type service-learning practice school. By the way, people said that 'why make things big?' Because if I had simply handled 10 hours of volunteer work before, I had to change it. I needed so much cooperation from other teachers. I was chasing another teacher. Persuading the process was so hard..

I think that the culture of the school must be changed in order to successfully succeed service-learning practice school. I think the culture will not change in a year or two. I think it will take about 5 years to settle the culture within the organization to some extent. But after 5 years I have to move to another school. Because the teachers are rotated, the quality of service-learning may or may not be good, depending on which person might be in charge of it. This is a major obstacle to the stabilization of service-learning. (19, 9, 20 teacher interview)

As a result of the interview, we found that it is difficult to persuade fellow teachers. There was a widespread perception that there were no major problems even if the service class was conducted without devotion. In particular, interviewees insisted that cultural awareness should be improved in order for continuity. It has been shown that improving service classes with one teacher in charge of service-learning causes a vicious cycle of work transition and job avoidance.

Teachers are not opposed to making service meaningful. However, the reality is that it is difficult to share their tasks and roles for leading service-learning. It is a situation that needs support in many ways, such as the leadership of the principal who can help improve the organizational culture, the help of the school board, and the reduction of work for fellow teachers.

4.1.2 Lack of Support System such as Budget: "Service should be done in a Volunteer Manner ..."

Joe: The budget keeps decreasing. The budget keeps dropping because the student is running out. You need about 10 million won to run servicelearning. 10 million won is not a lot of money. When it comes to 500 students, it's 20,000 won per person. If you hold a volunteer event about 5 times with 20,000 won, it will cost about 4,000 won at a time. In order to make 10 million won, 500 are brought from the village combined budget and 250 are brought through the service-learning practice school. I collect it here and there and run it.

A. My school had no budget last year. I applied for 200,000 won. 200,000 won. Last year, it was zero at all. The school just gave the students a garbage bag when they went out to clean the environmen... But the school asked me why do I need 200,000 won this yeal $\cdots$. saying again that at last year, no one used it. 
Some education-related offices support budgets for service-learning such as capacity-building projects. However, this was not systematic support. The amount of budget depends on the will and ability of the teacher. Teachers were running many kinds of budgets to run service-learning. Also, the school-wide budget for service-learning was very scarce. Teachers for service-learning had to take on tasks such as securing budgets, contacting relevant organizations, and persuading school members. The service support system was so weak that it depended on the individual teacher's ability. This made teachers reluctant to take on service.

\subsection{Center Representative}

\subsubsection{Lack of School Awareness of Volunteer Activities}

Kim The problem is that the teachers don't participate entirely. They want to leave it entirely to us and want to take it off. They want to hand it over and end it.

Jang: In order to succeed in service-learning practice school, not only the teacher in charge, but also all teachers must be interested However, the reality is that the teachers in charge have to do everything so they are also difficult. I felt his struggle. They are hard on their own, so they try to leave everything to us. In some parts, they want us to do what is fixed

Teachers tended to avoid service-learning due to heavy work. This can be seen as a lack of a system rather than a problem with teachers. When a mentor visits a school to help students in their service activities, the school may not be cooperating with the mentor or treat them as strangers. Awareness of service-learning makes volunteer work difficult.

4.2.2 The Link between Service-learning and the Curriculum: "We Learn, not just do Activities."

Park When students decide topics, it is usually based on what they learned If a volunteer mentor suggests a campaign to improve awareness, even though it is a very big topic, students usually think about just human rights. Because it's what they learned in class. Students made a campaign mainly based on what they learned in class, and they also run a campaign based on what they learned in history. So now I think we need to find a way to connect with volunteer work and curriculum

Yun: I think there are some points to be aware of when linking the curriculum and activities. There is a way to just throw out social issues and have students voluntarily plan. There is another way to choose a selected topic. By using the toolkit published by our city center we can make it random selection. In the former case, students are planning based on what they have learned, so the content can 
be uniform Attempting to combine with the curriculum is good, but as a result, it has the disadvantage of thinking only within the curriculum In the latter case, there was also the advantage of being able to graft a variety of topics.

The mentor wanted the content of the service to be linked to the school's curriculum. However, the mentor did not know the content of the curriculum. There was a practical difficulty in connecting the service activities with the curriculum.

In addition, when attempting to link the curriculum with service-learning, most students tended to do similar themes or activities, which shows that the curriculum linking leads to reduce creativity. In other words, the curriculum linkages need to try a variety of ways so that learning can occur simultaneously without compromising student creativity.

\section{Summary and Conclusion}

The contents of the interview are summarized as follows.

[Table 2] Interview Summary

\begin{tabular}{|c|c|c|c|}
\hline & Teachers & Centers / Mentors & Students/Parents \\
\hline \multirow{2}{*}{$\begin{array}{l}\text { Goals } \\
\text { and } \\
\text { contents } \\
\text { of } \\
\text { service-le } \\
\text { arning }\end{array}$} & \multicolumn{3}{|c|}{$\begin{array}{l}\text {-service-learning to cultivate student self-direction } \\
\text {-service-learning that provides an opportunity to reflect on life } \\
\text {-service-learning, such as a pathway that connects life with learning } \\
\text {-service-learning that leads student growth in connection with the curriculum }\end{array}$} \\
\hline & & $\begin{array}{l}\text {-Connection } \\
\text { service-learning process and } \\
\text { results }\end{array}$ & $\begin{array}{l}\text {-service-learning linked to } \\
\text { career paths }\end{array}$ \\
\hline Culture & \multicolumn{2}{|c|}{$\begin{array}{l}\text {-Need to raise teacher awareness in school } \\
\text {-Insufficient awareness of the principal's service-learning }\end{array}$} & . \\
\hline Budget & \multicolumn{2}{|c|}{-Insufficient budget and difficulty in using budget } & 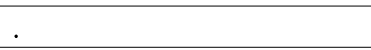 \\
\hline \multirow[t]{2}{*}{ Operation } & \multicolumn{2}{|c|}{$\begin{array}{l}\text {-Difficulty in cooperation and communication system } \\
\text { between school, autonomous district, and school board } \\
\text {-Difficulty coordinating schedules between schools and } \\
\text { centers } \\
\text {-Lack of manpower and lack of expertise } \\
\text {-Difficult to activate out-of-school service-learning due to } \\
\text { safety issues }\end{array}$} & . \\
\hline & \multicolumn{3}{|c|}{$\begin{array}{l}\text {-Difficulty in service-learning process and progress } \\
\text {-Dissatisfaction with how to record results } \\
\text {-Difficulty in reflecting school and student needs for } \\
\text { activities }\end{array}$} \\
\hline
\end{tabular}

Main issues are summarized as follows based on the above interview. 
First, in order to revitalize service-learning, awareness of service-learning should be improved and related concepts need to be clarified. Many educational studies have a similar tendency[11-14]. service-learning should be conducted in a way that reflects on student's life as well as enhance the ability to solve problems on their own, rather than just doing activities. Therefore, it is necessary to redefine the concept of service-learning and diversify the types of service-learning.

Second, cooperation should be diversified for the practical operation of service-learning. Teachers understand the meaning of service-learning and recognize the need for educational cooperation, but collaboration in real is difficult. service-learning is recognized as a task for some teachers. Especially in high school, college entrance exams are important, so there are many limitations to realizing service-learning. To overcome these difficulties, each actor must agree well with each other's needs. In addition, it is necessary to establish a channel for various cooperation.

Third, professional manpower or organization is needed to ensure continuous cooperation between the school and the community. They also need to specify their role. Currently, the center is in charge of the connection, and the mentor is in charge of the service. However, the reality is not that good. It is necessary to clarify what the stages are from planning to implementation and clarify what the roles are at each stage.

Fourth, the role of the teacher in service-learning is important. A plan should be prepared to utilize the nature of service-learning and at the same time lead the growth of the teacher himself. For this, a cooperative support system is needed between the school, the community, and the borough centers.

Fifth, it is necessary to devise a way to ensure safety. A significant obstacle to out-of-school service-learning is a safety problem that can occur in student mobility. Therefore, various measures for this should be sought.

\section{Acknowledgement}

This study was funded by Hankuk University of Foreign Studies.

\section{References}

[1] Yong-Ha Joh, A Study on Theoretical Framework of College Volunteering with special reference on service learning, Korean Journal of Youth Studies, (2002), Vol.9, No.3, pp.243-268. 
[2] Won Pyo Hong, How to enhance the educative function of school-based community service: Integrating service and learning, The Journal of Curriculum Studies, (2013), Vol.31, No.3, pp.227-251.

[3] Kielsmeier, J. C., Build a bridge between service and learning, Phi Delta Kappan, (2010), Vol.91, No.5, pp.8-15, DOI: https://doi.org/10.1177/003172171009100503

[4] Kim. D. J., The Impact of Volunteer Activities on Social Development in Adolescence, Korean Academy of Social Welfare Support, (2009), Vol.4, pp.123-146.

[5] Billig, S., Research on K-12 school-based service-learning: The evidence builds, Phi Delta Kappan, (2000), Vol.81, No.9, pp.658-664.

[6] Kendall, J. C., Combining service and learning: An introduction, Combining service and learning: A resource book for community and public service, (1990), Raleigh, NC: National Society for Experiential Education.

[7] Wade, R. C. (Ed.), Community service-learning: A guide to including service in the public school curriculum, USA: SUNY Press, (1997)

[8] Mann, Sheilah, Patrick, John J., Education for civic engagement in democracy: service-learning and other promising practices, (2000), USA: ERIC Publications. pp.45-59, https://eric.ed.gov/?id=ED447065

[9] Furco, Andrew, Billig, Shelley H., Service-Learning: The Essence of the Pedagogy. Advances in Service-Learning Research., (2002), Collected Works - General, https://eric.ed.gov/?id=ED462631

[10] Alice Y. Kolb, David A. Kolb, The Kolb Learning Style Inventory-Version 3.12005 Technical Specifications. USA MA: Hay Resource Direct, (2005).

[11] Kim Pyong Ho, Formative Assessment Methods to Resolve Curriculum and Summative Assessment-related Issues, Asia-Pacific Journal of Educational Management Research, (2019), Vol.4. No.2, pp.1-6.

[12] Lee Myungsook, Aekyeong Yang, Factors influencing to 21st Century Skill of College Student, Asia-Pacific Journal of Educational Management Research, (2019), Vol.4. No.2, pp.7-14.

[13] Joo Soon-ok Joo, Cho Sung-je, The Effect of Teacher Efficacy of Early Childhood Teachers on Teacher Happiness, Asia-Pacific Journal of Educational Management Research, (2019), Vol.4. No.2, pp.15-22.

[14] Liu Wei, Research on the Innovation of College Students' Employment Guidance in the Age of Big Data, Asia-Pacific Journal of Educational Management Research, (2019), Vol.4. No.2, pp.23-32. 